\title{
Sequence Variability of Hepatitis B Virus (HBV) Surface Antigen Gene (S Gene) Among the Non- responders of Antiviral Therapy
}

Naveed Alam ( $\sim$ naveed.alam@mail.kmutt.ac.th )

King Mongkut's University of Technology Thonburi https://orcid.org/0000-0002-7125-9891

Zubaida Daudzai

King Mongkut's University of Technology Thonburi

\section{Research}

Keywords: Hepatitis B Virus (HBV), Surface mutations, Surface gene, sequence analysis, Khyber Pakhtunkhwa

Posted Date: October 5th, 2021

DOI: https://doi.org/10.21203/rs.3.rs-898537/v1

License: (c) (i) This work is licensed under a Creative Commons Attribution 4.0 International License.

Read Full License 


\section{Abstract}

\section{Background}

Hepatitis B Virus (HBV), has been among the wide spread lethal causative agent of mortality in the population of Pakistan. Prolonged administration of antiviral therapy for chronic hepatitis B may result in the development of hepatitis B viral mutants.

\section{Objectives}

To gain insight into the mechanism involved in the sequence variability of Hepatitis B Virus (HBV) surface antigen gene (S gene) among responders and non-responders to antiviral therapy, baseline characteristics of the patients and sequences within the $S$ region were investigated in pre-treatment serum samples of responders and post-treatment serum samples of non-responders.

\section{Data collection and methodology}

The data was collected from 15 individuals with chronic hepatitis B from Khyber Pakhtunkhwa (KPK) province, Pakistan. The antiviral response was independent of viral genotypes, and nonresponse to antiviral therapy was associated with a complex variability of the viral mutants as determined by PCR.

Results

The sequence analysis of the $S$ gene among responders and non-responders patients of pre and posttreatment with antiviral therapy showed variability in DNA sequence marked as Pakistani isolates make a distinct cluster in the phylogenetic tree. The $S$ gene of HBV isolates from KPK province shows some similarities with isolates of other countries. No significant variations of nucleotides in the S gene of HBV was found among the responders and non-responders receiving antiviral therapy indicating that $S$ gene may not be important with respect to treatment outcome.

\section{Conclusion}

It illustrates that antigenicity of other various HBV proteins can be targeted in order to design more effective vaccines against the local strains.

\section{Introduction}

Hepatitis B is a serious public health problem worldwide. Initially it causes acute liver diseases that might also lead to chronic stages including liver cirrhosis and hepatocellular carcinoma (Moola et al., 2002). Studies showed that about two billion of people are infected worldwide from the time of its discovery (Dokanehiifard et al., 2009), that is expectedly causing about 600,000 deaths annually (Guirgis et al., 2010). Hepatitis B is caused by Hepatitis B Virus (HBV), which falls in the Hepadna virus family and is believed to the only human demonstrative of this family (Patricia et al., 1997). HBV is categorized into 
eight genotypes, i-e A to $\mathrm{H}$, which is based on the intra-group nucleotide deviation in $\mathrm{S}$ genome and whole genome sequences up to $4.2 \%$ and $>8 \%$,respectively (Zhu CT et al, 2009; Guirgis et al, 2010; Eftekhari et al., 2010; Khaled et al., 2010), which comprises of about 3200 base pairs (Khaled et al., 2010). HBV has a rounded and partly double stranded DNA genome with $3.2 \mathrm{~kb}$ in size which contains four overlying open reading frames (Hideo et al., 2000). The four known genes of HBV encoded by the genome are called C, P, $S$ and X. Gene S codes for the surface antigen (HBsAg) which has been defined as the molecular basis for the serologic heterogeneity (Norderet al., 1992). Moreover, on the basis of limited sequencing contained by the $S$ gene, the HBV genotyping is viable, with results reliable with those established on the sequencing of complete genomes (Sloan et al., 2008; Warner et al., 2008; Yeh et al., 2010; Benedikt Simon et al., 2012).

Mutation in the S region of genome of the variants of hepatitis B virus (HBV) occurred and emerged (Pollicino et al., 2014). Simon et al. (2012) reported that the genome of Hepatitis B virus (HBV) indicate a high rate of mutations, resulting in a variety of changes in the amino acid, which can change the conformation of viral proteins, as a result antibody binding is reduced or the secretion of surface antigen (HBsAg) is diminished. Few types of pre-S mutants in patients arising naturally in the hepatic tissue or serum infection have been noticed (Yu-Fen Fan et al., 2001). Whereas, in molecular based assays and immunologic sensitivity, a challenge is represented by the genetic variability of hepatitis $B$ virus (HBV) (Weber et al., 2004). Along with, structurally modified nucleotide/nucleoside analogues exerts potent inhibitory effect on HBV polymerase activities (CT at al., 2010). During long-term therapy, mutations happened not merely in the polymerase gene but also in the $S$ gene, produced increase of two types of surface protein mutants. It was also recognized that $5-10 \%$ hepatitis $B$ adult vaccines were non- and hypo-responders and possibly were not effectively protected against hepatitis B virus (HBV) infection affecting the duration and intensity of protective humoral immune response to the hepatitis $B$ vaccine (Chen et al., 2010).

Studies on vaccinations has been made but certain limitation suggests further improvement in term of long term effects (Ljunggren et al., 2004). In addition to regular evolutionary variations that participates in genetic changes, vaccination or antiviral therapy also contribute in the mutations process. Okamoto et al. (1992) stated that a variant of hepatitis B virus (HBV) having a specific mutation within the S gene has been found to infect vaccines. Yamamoto et al. (1993) reported that HBV escape mutants with mutations in the $S$ gene affecting the expression of group-specific determinants would survive in some carriers after they seroconvert to antibody against surface antigen. Carriers with HBV escape mutants may transmit HBV either by donation of blood units without detectable surface antigen or through community-acquired infection, which would hardly be prevented by current hepatitis B immunoglobulin or vaccines. The lack of identical sites in most of its coding sequence and also the frequent change in the amino acid of its precore and $\mathrm{S}$ gene region give an additional property towards successful dogging the immune system (Simmonds, 2001; Alam et al., 2007). Based on the perspective, the central hypothesis of this study is to investigate the sequence variability of $S$ gene of $\mathrm{HBV}$ among the non-responders of antiviral therapy by amplification and sequencing of the $S$ gene of HBV by qualitative PCR. Moreover, the genetic linkage was carried out phylogenetic analysis using different bioinformatics tools. 


\section{Materials And Methods \\ 2.1 Sample collection:}

Hepatitis B virus infected patients (HBsAg positive patients $(n=150)$ ) from both genders of age $(18-55)$ years at three different general hospitals of Khyber Teaching Hospital Peshawar, Hayat Abad Medical Complex Peshawar and Lady Reading Hospital Peshawar were randomly included in this study from period of September 2015 to February 2016. The inclusion criteria was selected for those patients whose PCR results were still positive after completing their alpha interferon therapy (Antiviral therapy). Whereas, the patients whose PCR results came negative after completing antiviral treatment were excluded.

\subsection{Hepatitis B Serology analysis:}

All patients were screened for HBsAg using rapid test strip (ACON Laboratories Inc. San Diego. CA, USA). The confirmation of all HBsAg positive were made using 3rd generation enzyme linked immunosorbent assay (Bio-Rad Berkeley, California) according to manufacturer's instructions. Initial screening was conducted through Immuno Chromatography Technique (ICT) (BD USA) strips. All the patients were further confirmed by the presence of HBV through ELIZA (Bio-Rad Berkeley, California). Serum was separated for serology tests by centrifuging whole blood $5000 \mathrm{rpm}$ for 4 min using micro centrifuge (Sigma D-37520, Germany). The serum samples were then stored at $-20^{\circ} \mathrm{C}$ immediately.

\subsection{Antiviral Therapy analysis:}

Alpha interferon therapy treatment was done for 3 months. And then their serum was taken and PCR ( $T 100^{\mathrm{TM}}$ Thermal Cycler BIO RAD USA) was performed, patients who were still positive and did not respond to the antiviral therapy (non-responder) and contained the virus in their blood was further investigated in the study. Whereas, patients whose PCR results came negative and cleared all the viruses from their blood and showed response to the antiviral therapy were classified as responder.

\subsection{Amplification and documentation of HBV Surface gene (S gene):}

HBV DNA was extracted from both antiviral responder and non-responder samples using commercial viral DNA extraction kit (Favorgen Biotech Corporation, Pingtung, Taiwan) according to manufacturer's instructions. The extracted HBV DNA was stored at $-20^{\circ} \mathrm{C}$ prior to DNA amplification for further use. The extracted stored HBV DNA was of responders and non-responders were used for the amplification of $S$ gene. The extracted DNA was amplified using S-gene specific primer i.e. Forward Primer 5/-GGTATGTTGCCCGTTTGTCCTCT-3/and Reverse primer 5/-'GGCACTAGTAAACTGAGCCA-3'. Nested PCR reaction was carried out using a total volume of $20 \mu \mathrm{L}$ including $2 \mu \mathrm{L}$ of DNA extract, $1 \mu \mathrm{L}$ of forward primer, $1 \mu \mathrm{L}$ of reverse primer, $4 \mu \mathrm{L}$ of Magnesium chloride, $0.5 \mu \mathrm{L}$ of Taq polymerase, $2 \mu \mathrm{L}$ of Taq buffer, $2 \mu \mathrm{L}$ of DNTPs and $7.5 \mu \mathrm{L}$ of distilled water. Amplification was carried out in PCR (T100 ${ }^{\mathrm{Tm}}$ Thermal Cycler BIO RAD USA) using the following protocol: Initial denaturation at $95^{\circ} \mathrm{C}$ for $5 \mathrm{~min}, 30$ cycles at $95^{\circ} \mathrm{C}$ for 30 sec, $57^{\circ} \mathrm{C}$ for $30 \mathrm{~s}$ and $72^{\circ} \mathrm{C}$ for $30 \mathrm{~s}$ and final extension at $72^{\circ} \mathrm{C}$ for $10 \mathrm{~min}$. The amplified PCR products 
were visualized using $2 \%$ agarose gel pre-stained with ethidium bromide. Visualization of amplified PCR products was made using (Uvitec Limited, Cambridge, UK) gel documentation system.

\subsection{Phylogenetic analysis of S gene:}

The S gene product was separated from agarose gel and purified using gel purifying kit (Thermo Fisher Scientific, USA) according to the manufacturer's instructions. Sequencing was performed at Korea through Macrogen by using Big Dye Deoxy Terminator method. (Applied Biosystems) with the help of a private company (Worldwide Scientific Islamabad). Phylogenetic tree of the HBV S gene nucleotide sequences isolated from Responders and non-responders was constructed with the HBV Surface gene sequences retrieved from NCBI of various geographical regions of the world by using Mega6.

\section{Results}

\subsection{Antiviral Therapy analysis:}

Since Hepatitis B virus (HBV) infection is described by a high rate of development of chronic infection with either high- or low-titer viremia (Gunther et al., 1999), the results of which include cirrhosis or hepatocellular carcinoma (Lee et al., 1997). Variability in the genome of HBV is involved as one of the mechanisms in viral existence. In fact, HBV duplicates its DNA genome via a reverse-transcription step (Summers et al., 1982), and the rate of spontaneous error of the reverse transcriptase (RT) proceeds to the occurrence of mutations which may collected or be selected during the course of infection. Eight genotypes (A to H) of hepatitis B virus (HBV) have been defined so far (Schaefer et al., 2007). For the identification of sequence variability of HBV S gene among the 10 non-responder samples of antiviral therapy, 5 responder samples were also taken as control group. Initial screening was done through ICT and ELIZA followed by PCR. The study involved $150 \mathrm{HBV}$ infected patients who were referred to several health care units of KPK; qualitative detection of HBV DNA was done for finding of active infection. Among 150 patients, only 10 patients did not show response to the antiviral therapy and the rest showed response and cleared the Viral DNA.

\subsection{Identification of S gene}

The basic purpose of current study was to identify and characterize the sequence variability of HBV S gene among the non-responders of antiviral therapy. For this reason we designed a study to find out HBV $S$ gene sequences of responders and non-responders by qualitative PCR followed by sequencing among the actively infected patients Fig. 2 . The samples selection was irrespective of the gender. In our study, 5 responder and 10 non-responder samples of HBV were sequenced for $230 \mathrm{bp}$ fragment of surface gene, which make the envelop protein for HBV. After sequencing and bioinformatics analysis we find out that our isolates of HBV formed a distinct cluster in the phylogenetic tree. This showed that Pakistani isolates of HBV have distinct sequences as compared to other countries and showing a great rate of sequence variability in the surface (S) gene of HBV because of high rate of mutation due to antiviral therapy. 


\subsection{Phylogenetic analysis}

Sequencing of HBV S gene was carried out for identification of sequence variability. There were no significant sequence variation among the Responders and non-responders. Nucleotide sequence analysis of the obtained sequences based on HBV S gene sequences with reference sequences from different countries showed that our sequences clustered with some local and regional sequences with high bootstrap values. Bioinformatics tools were used to translate the attained nucleotide sequences to amino acid sequences. To search for alike sequences, the obtained sequences were used using BLAST algorithms against NCBI non-redundant nucleotide and online database of protein. BLAST investigation further established that reported sequences had high resemblance among the responders and nonresponders of the surface gene of HBV. Collected sequences were used to build phylogenetic tree by using Maximum likelihood (Lole et al., 2003) algorithms. Evolutionary analysis revealed that our reported sequences of HBV S gene, clustered with Pakistani isolates. Although they were closely related and evolved together but again were distinct from other countries. The $S$ gene of HBV responders and nonresponders was amplified and sequenced. BLAST analysis was performed and $S$ gene sequences having homology with reported sequences were selected randomly for phylogenetic analysis. For finding sequence variation among responder and non-responder, the $S$ gene of 15/150 HBV samples (5 responder, 10 non-responder) was amplified and sequenced. Sequence blasting was also performed between responder and non-responder sequences. Phylogenetic analysis was carried out and a Maximum Likelihood algorithm (1000 bootstrap replicates) tree was developed from the sequences obtained from our study and sequences retrieved from NCBI of various geographical regions of the world Fig. 3. In nucleotides-based tree by ML method, reported sequences of responders and non-responders were observed.

\section{Discussion}

From Fig. 1, 6.66\% patients with active infection were detected while $93.33 \%$ patients were found to have no infection after taking antiviral therapy. About 5 (3.33 \%) PCR positive samples of responders were investigated. Each genotype appears to have a limited geographical distribution; consequently, it establishes an invaluable means in finding HBV molecular progression and the arrangement and methods in which HBV spreads (Miyakawa et al., 2003). This variety may be accountable for the selection of mutants that escape the immune response to the hepatitis B e antigen (HBeAg; i.e., the pre core region mutants), the immune response to the hepatitis B surface antigen (HBsAg; i.e., the surface gene mutants), or the capsid T cell response (i.e., the core gene mutants) (Gunther et al., 1999). On the other hand, mutants may be more modified to definite host circumstances, such as immunodeficiency or antiviral therapy, and may outgrow wildtype virus (Zoulim et al., 1998).

The emergence and takeover of hepatitis B virus (HBV) variants carrying mutation(s) in the preS/S genomic region is a fairly frequent event that may occur spontaneously or may be the consequence of immune prophylaxis or antiviral treatments. Selection of preS/S mutants may have relevant pathobiological and clinical implications. The variation of the natural course of the infection and related 
disease is determined by the interaction between virus and host factors (Chisari et al., 1995). Several lines of evidence indicate that a certain number of HBV genetic variants, apparently provided with higher pathogenicity, may emerge during the course of the infection under endogenous (host immunity) and/or exogenous (immune prophylaxis and antiviral therapies) selection pressures (Locarnini et al., 2010).

From Fig. 3, a nucleotide based phylogenetic tree constructed with 30 reported sequences of other countries showed that the sequenced isolates grouped as a separate clade which indicated their relatively close relationship with one another and distinct nature from HBV isolates of the other countries. Our sequences clustered together with Pakistani isolates and also showed high homology with the sequences of Saudi Arabia and India with strong bootstrap value. Hence showed that it may be due to trade, travel and communication between these countries. It is suggested that for our sequences dataset, ML tree should be made by using character-based tree to compare our sequences with other countries. In current study the ML tree methods showed and hence verified that our sequences made a distinct cluster in the $\mathrm{ML}$ tree and indicated that there is much sequence variability in HBV S gene of Pakistani isolates related to $S$ gene reported sequences from NCBI. Klaus et al. (2000) reported that hepatitis B chronic carriers typically indicate HBV surface antigen (HBsAg) in their sera, which is thought the best indicator for mild and chronic infection of HBV. In some individuals, though, routine serological assays cannot detect this antigen in spite of the existence of virus in liver and peripheral blood. The lack of HBsAg might be one of the reasons of mutations in the part of the molecule detected by specific antibodies. The $S$ gene sequences of HBV were determined of samples from 33 virus carriers who were negative for HBsAg but showed antibodies against the virus core (anti-HBc) as the only hepatitis B serological marker. These outcomes recommend that at least some of the chronic low-level HBV carriers, where surface antigen is not identified, might be infected by diagnostic escape mutants and/or by variants with impaired replication. So our study also concluded that as a result of frequent mutation occurs in HBV due to antiviral therapy, there is variation in HBV S gene as our reported sequences made a distinct cluster in phylogenetic tree as compared to $S$ gene sequences of other countries. With reference to this, our study suggested that the surface antigen gene of HBV isolates from KPK province showed some similarities with isolates of other countries. No significant variations of nucleotides in the surface gene of HBV was found among the responders and non-responders of antiviral therapy indicating that surface antigen gene may not be important with respect to treatment outcome. Antigenicity of various HBV proteins be determined in order to design more effective vaccines against local strains.

\section{Conclusion}

This study reveals that HBV surface antigen gene shows variability in DNA sequence as Pakistani isolates make a distinct cluster in the phylogenetic tree. However, the surface antigen gene of HBV isolates from KPK province showed some similarities with isolates of other countries. No significant variations in nucleotides of the surface gene of HBV was found among the responders and nonresponders to antiviral therapy indicating that surface antigen gene may not be important with respect to treatment outcome. Hence, the evolutionary analysis of HBV S gene presented important perceptions on its origin, progression and grade of genetic diversity. Phylogenetic analysis on the base of sequences of 
full genome or more than one gene is necessary for better characterization of this variant and it will be very useful in clinical management.

\section{Abbreviations}

Hepatitis B Virus (HBV); Khyber Pakhtunkhwa (KPK); surface antigen gene (S gene); hepatitis B e antigen (HBeAg); hepatitis B surface antigen (HBsAg); reverse transcriptase (RT); Immuno Chromatography Technique (ICT).

\section{Declarations}

\section{Ethics approval and consent to participate}

Not applicable

\section{Consent to publication}

Not applicable

\section{Availability of data and materials}

All data generated or analysed during this study have no supplementary data.

\section{Disclosure of competing interests}

The authors declare that they have no known competing financial interests or personal relationships that could have appeared to influence the work reported in this paper.

\section{Funding}

No funding source

\section{Authors Contributions}

NA and ZD conceived the idea and design the experiments.

\section{Acknowledgements}

NA conducted the experiments and ZD draft the manuscript. All the authors analyzed the experimental data, discussed and finalized the manuscript.

\section{References}

Alam, M. M., S. Z. Zaidi , S. A. Malik, S. Shaukat, A. Naeem , S. Sharif , M. Angez and J. A. Butt. 2007. Molecular epidemiology of Hepatitis B virus genotypes in Pakistan. BMC. Infect. Dis. 7:115. 
Arauz, R. P., H. Norder , B. H. Robertson, L. O. Magnius and H. Genotype. 2002. a new Amerindian genotype of hepatitis B virus revealed in Central America. J. Gen. Virology. 83(8): 2059-2073.

Beck, J and M. Nassal. 2007. Hepatitis B virus replication. World J. Gastroenterology. 13(1): 48-64.

Bernard, Weber. 2004. Genetic variability of the S gene of hepatitis B virus. Clinical and diagnostic impact. Journal of Clinical Virology. (32): 102-112.

Bouchard, M. J, and R. J. Schneider. 2004. The enigmatic X gene of hepatitis B virus. Journal of virology. 78(23): 12725-34.

C. T. Yeh. 2010. Development of HBV S gene mutants in chronic hepatitis B patients receiving nucleotide/nucleoside analogue therapy. Antiviral Therapy. 15(3):471-475.

Chisari, F. V and C. Ferrari. 1995. Hepatitis B virus immuno pathogenesis. Annu. Rev. Immunology. 13:2960.

Dokanehiifard, S and A. Bidmeshkipour. 2009. Study of Hepatitis B Virus (HBV) Genotypes in Kermanshah Province, West of Iran. eJournal of Biological Sciences. 1(1):113-120.

Eftekhari, Y., M. K. Arababadi, H. Hakimi and E. R. Zarandi. 2010. Common HBV Genotype in Southeastern Iranian Patients. Arch. Iran Med. 13(2):147-149.

Guirgis, B. S. S., R. O. Abbas and H. M. E. Azzazy. 2010. Hepatitis B virus genotyping: current methods and clinical implications. International Journal of Infectious Diseases. 941-953.

Gunther, S., L. Fischer, I. Pult, M. Sterneck and H. Will. 1999. Naturally occurring variants of hepatitis B virus. Adv. Virus Res. (52): 125-137.

Hideo, N., S. Hayashi and K. Abe. 2000. Rapid and Specific Genotyping System for Hepatitis B Virus Corresponding to Six Major Genotypes by PCR Using Type-Specific Primers. Journal of Clinical Microbiology. (39): 362-364.

Kaya, A. B and F. Zoulim. 2007. Hepatitis B virus genetic variability and evolution. Virus Research. (127): 164-176.

Khaled, I. A., O. M. Mahmoud, A. F. Saleh and E. A. Baioumi. 2010. Prevalence of HBV Genotypes in Egypt among Hepatitis Patients. Journal of American Science. 6(11): 185-190.

Kim, H.J., J. H. Park, Y. Jee, S. A. Lee, H. Kim, B.C. Song, S.Y. Yang, M. H. Lee, J. H. Yoon, H. J. Kim, H. S. Lee, E. S. Hwang, Y. H. Kook and B. J. Kim. 2008. Hepatitis B virus X mutations occurring naturally associated with clinical severity of liver disease among Korean patients with chronic genotype $\mathrm{C}$ infection. J. Med. Virology. (80): 1337-1343. 
Klaus, M., B. Weinberger, B. Tanja, B. Stephan and J. Wolfgang. 2000. High genetic variability of the group-specific a-determinant of hepatitis B virus surface antigen (HBsAg) and the corresponding fragment of the viral polymerase in chronic virus carriers lacking detectable HBsAg in serum. Journal of General Virology. (81): 1165-1174.

Lee, W. M. 1997. Hepatitis B virus infection. N. Eng. J. Med. (337): 1733-45.

Locarnini, S and F. Zoulim. 2010. Molecular genetics of HBV infection. Antivir. Ther. (15): 3-14.

Miyakawa. Y and M. Mizokami. 2003. Classifying hepatitis B virus genotypes. Intervirology. (46): 329338.

Moolla, N., M. Kew and P. Arbuthnot. 2002. Regulatory elements of hepatitis B virus transcription. J. Viral Hepatology. (9): 323-331.

Norder, H., A. M. Courouce and L. O. Magnius. 1992. Molecular basis of hepatitis B virus serotypes variations within the four major subtypes. J. Gen. Virology. (73): 3141-3145.

Norder, H., B. Hammas, S. D. Lee, K. Bile, A. M Courouce and I. K. Mushahwar. 1993. Genetic relatedness of hepatitis B viral strains of diverse geographical origin and natural variations in the primary structure of the surface antigen. J. Gen. Virology. (74): 1341-1348.

Okamoto, H., K. Yano, Y. Nozaki, A. Matsui, H. Miyazaki, K. Yamamoto, F. tsuda, A. Machida and S. Mishiro. 1992. Mutations within the S Gene of Hepatitis B Virus Transmitted from Mothers to Babies Immunized with Hepatitis B Immune Globulin and Vaccine. (32): 264-268.

Okamoto, H., M. Imai, M. Kametani, T. Nakamura and M. Mayumi. 1987. Genomic heterogeneity of hepatitis B virus in a 54-year-old woman who contracted the infection through materno-fetal transmission. Jpn. J. Exp. Med. (57): 231-6.

Schaefer, S. 2005. Hepatitis B virus: significance of genotypes. J. Viral Hepatology. (12): 111-124.

Schaefer, S. 2007. Hepatitis B virus taxonomy and hepatitis B virus genotypes. World J. Gastroenterology. (13): 14-21.

Sloan, R. D., S. Ijaz, P. L. Moore, T. J. Harrison, C. G Teo and R.S Tedder. 2008. Antiviral resistance mutations potentiate hepatitis B virus immune evasion through disruption of its surface antigen a determinant. Antivirology Ther. (13): 439-447.

Stuyver, L., D. S. Gendt, V. C. Geyt, F. Zoulim, M. Fried, R. F. Schinazi and R. Rossau. 2008. A new genotype of hepatitis B virus: complete genome and phylogenetic relatedness. J. Gen. Virology. (81): 67-74.

Summers, J and W. S. Mason. 1982. Replication of the genome of a hepatitis B-like virus by reverse transcription of an RNA intermediate. Cell. (29): 403-15. 
Torresi, J., E. L. Silveira, G. Deliyannis, K. Edgtton, H. Zhuang, S. A. Locarnini, J. Fyfe, T. Sozzi and D. C. Jackson. 2002. Virology. (293): 305-313.

Warner, N and S. Locarnini. 2008. The antiviral drug selected hepatitis B virus rtA181T/sW172 mutant has a dominant-negative secretion defect and alters the typical profile of viral rebound. Hepatology. (48): $88-98$.

Whalley, S. A., D. Brown , G. J. Webster , R. Jacobs , S. Reignat , A. Bertoletti , C. G. Teo, V. Emery and G. M. Dusheiko. 2004. Evolution of hepatitis B virus during primary infection in humans: transient generation of cytotoxic T-cell mutants. Gastroenterology. (127): 1131-1138.

Yeh, C. T., R. N. Chien, C. M. Chu and Y. F. Liaw. 2000. Clearance of the original hepatitis B virus YMDDmotif mutants with emergence of distinct lamivudine-resistant mutants during prolonged lamivudine therapy. Hepatology. (31): $1318-1326$.

Zoulim, F and C. Trepo. 1998. Drug therapy for chronic hepatitis B: antiviral efficacy and influence of hepatitis B virus polymerase mutations on the outcome of therapy. J. Hepatology. (29): 151-68.

\section{Figures}

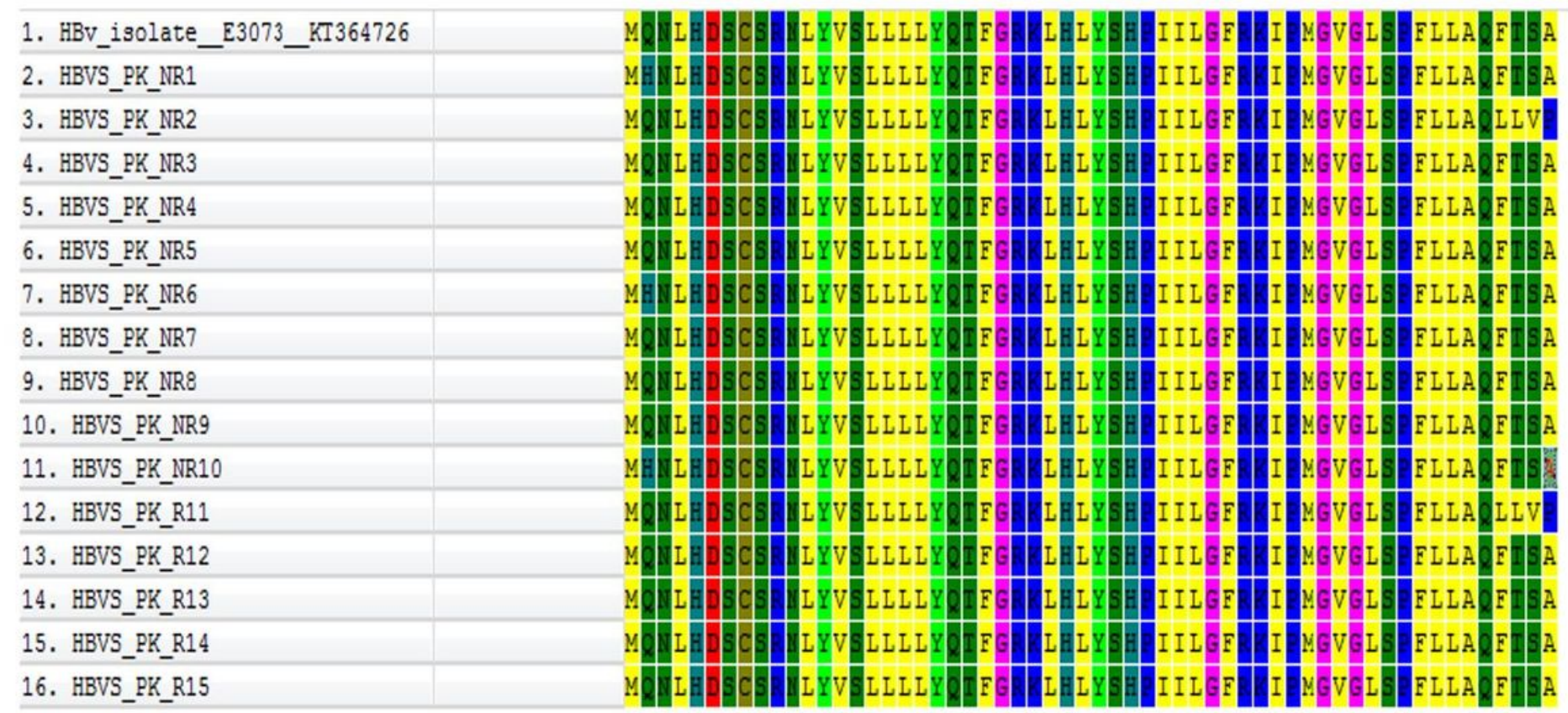

\section{Figure 1}

Alignment of S gene sequences of responders and non-responders to find out the mutation and identity between the sequences. 


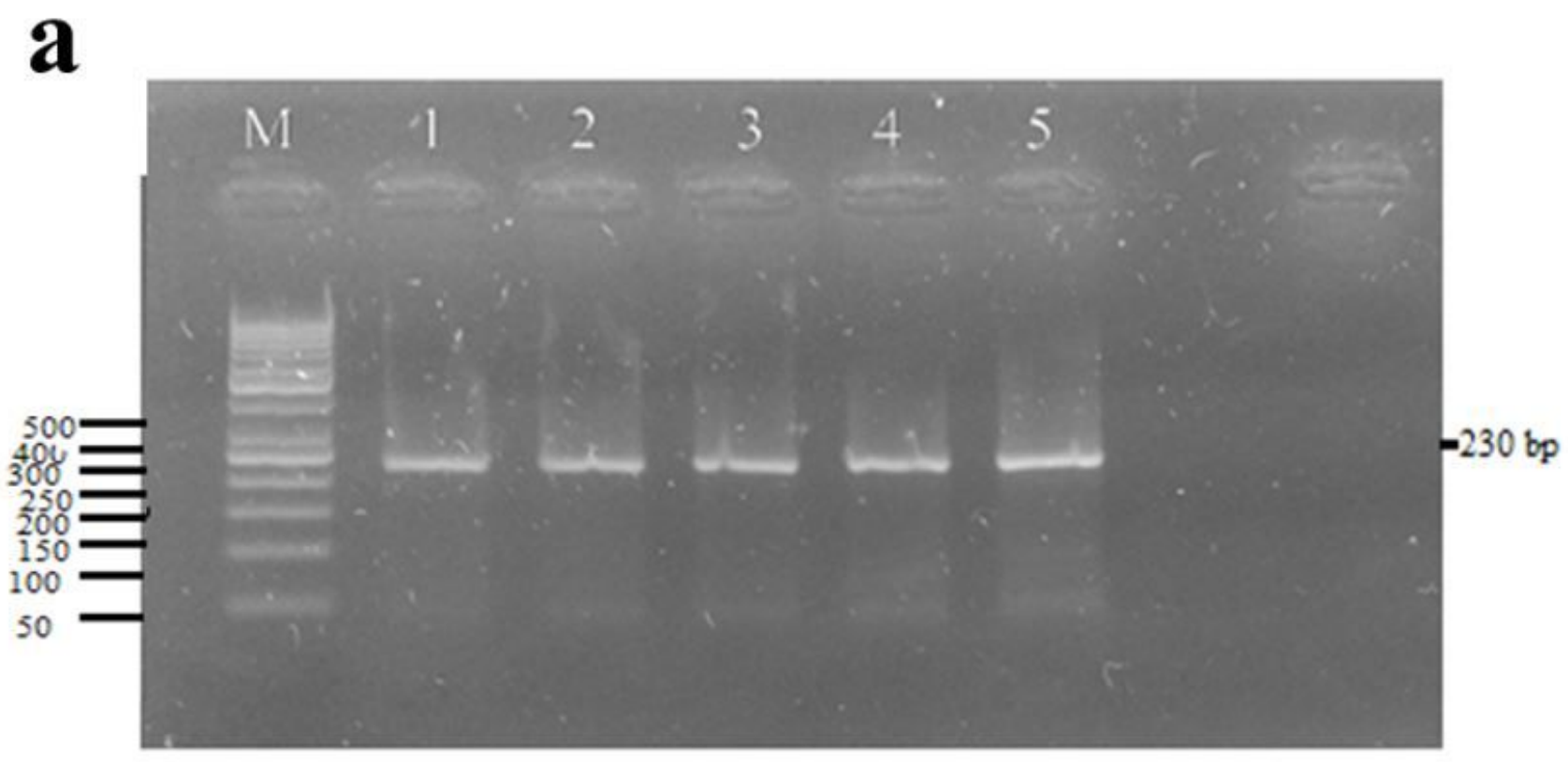

b

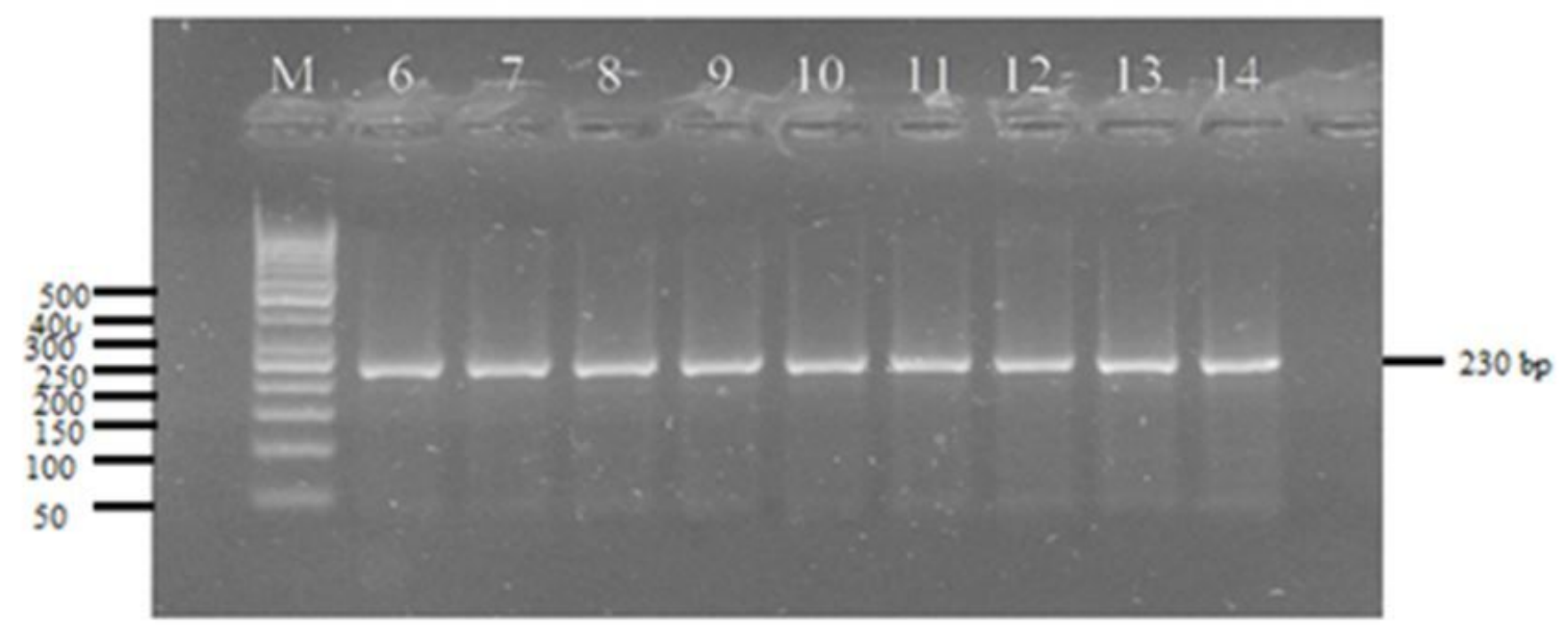

\section{Figure 2}

Gel picture of the PCR amplification of S gene (230bp) of responders (a) and non-responders (b). Lane M showing DNA ladder of 50bp; Lane 6-15 representing HBV positive samples of non-responders with $230 \mathrm{bp}$ of $\mathrm{S}$ gene. 


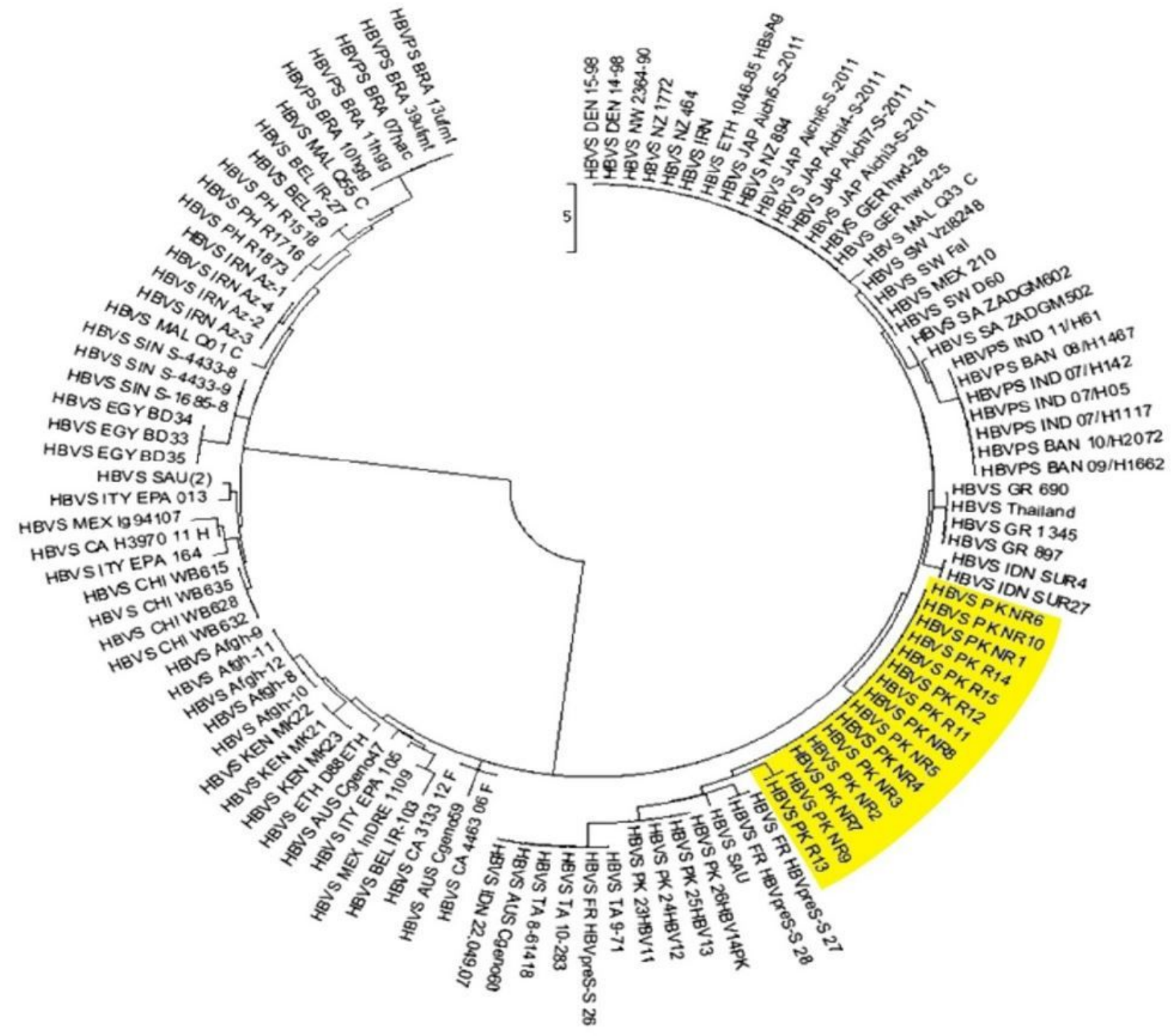

Figure 3

Nucleotide based ML tree generated from the sequencing of surface antigen gene (S gene) and its relation with variants in other countries. 